\title{
MAKING LASER SAFETY TRAINING MORE COGNITIVELY EFFECTIVE: MAKING TRAINING VIDEOS INTERACTIVE AND ADAPTIVE
}

\author{
Paper (802)
}

\author{
Tom Cherrett ${ }^{1}$, James C. Gates ${ }^{2}$, Pearl John ${ }^{3}$, Laura Holdaway-Salmon ${ }^{4}$, Joseph Price ${ }^{5}$, Gary B. Wills ${ }^{5}$, \\ Itiel E. Dror ${ }^{4}$ \\ ${ }^{1}$ School of Civil Engineering and the Environment, University of Southampton, UK \\ ${ }^{2}$ Optoelectronics Research Centre, University of Southampton, UK \\ ${ }^{3}$ School of Physics and Astronomy, University of Southampton, UK \\ ${ }^{4}$ School of Psychology, University of Southampton, UK \\ ${ }^{5}$ School of Electronics and Computer Science, University of Southampton, UK
}

\begin{abstract}
The cost of health and safety failures to UK industry is currently estimated at $£ 6.5$ billion per annum. Better health and safety education (particularly retraining) across all skill levels is seen as an integral part of any solution. Traditional lecture-based courses often fail to re-create the dynamic realities of managing health and safety on-site or in-the-lab, and therefore do not sufficiently engage the students in deeper learning (which results in remembering and using what was learned). Current training regimes also have to adapt to increasing numbers of overseas students/employees who often display different attitudes towards health and safety and the perception of risk.
\end{abstract}

The use of video as a training aid is common place, but passively observing a video is not cognitively engaging and therefore learning is not as effective as it could be. This paper will describe the development and testing of an interactive and adaptive video designed to help students understand the risks involved with the set-up and operation of lasers in a laboratory setting. The software allows students to interact and engage with the subject matter by requiring them to identify and describe risks through the technique of video 'hot-spotting' coupled to multiple choice question sets.

\section{Introduction}

In the mid 1980s the University of Southampton produced the laser safety training video 'Laser safety in Higher Education'. Today most UK institutions still use the video as their core teaching tool. The video was funded by the Committee of ViceChancellors and Principles of the Universities of the United Kingdom. (CVCP) which also produced the Laser Safety in Universities: Notes of Guidance Part
2:1 Lasers, which was revised in 1992 and still used as a teaching tool at university.

At the University of Southampton laser safety is taught via the video presentation, lecture/discussion and lab demonstrations. Academic staff members, technicians and postgraduate student demonstrators oversee safety in the lab by reminding undergraduate students of safety issues during experiments.

While the video has been very successful as an overview and introduction to laser safety, there are elements within it that have become obsolete due to changes in legislation. The video refers to a laser safety classification system which is now no longer used in the UK. Photonics technology has also developed substantially over the last twenty-five years and as a result the video no longer illustrates equipment currently used in University laser laboratories. Lastly, students find the video slightly comical as the presenter and equipment appear outdated, being produced in the 1980's.

In addition to the changes made in laser-related legislation over the past 25 years, health and safety in the UK has also undergone changes in emphasis. Employers now have a duty of care to ensure that any risks to their employees/students have been sufficiently assessed and the risks mitigated. Producing a written risk assessment for lab experimentation is now obligatory. One of the greatest challenges for employers is to train staff and students - especially those new to the UK legislation - to identify hazards, mitigate for the risks and document them.

Instead of updating the laser safety video, a more effective laser safety training prototype has been designed utilizing state-of-the-art interactive and adaptive software technology, demanding a higher level of cognitive engagement from the students 
compared to video alone. This interactive and adaptive laser safety software tool has been shown to be a more effective teaching aid than a video as demonstrated in our experiment.

This paper looks at the development of that prototype which has been designed to be used in conjunction with the passive University of Southampton video. The interactive software not only consolidates the information shown in the video, but also teaches hazard perception. The paper outlines how an understanding of cognitive processes and the use of new media can complement conventional teaching methods.

\section{The development and benefit of interactive video}

Video streaming has been extensively used to support and facilitate learning, $[1,2,3,4]$ but one of its major drawbacks is the inability of the learner to fully interact with the medium and the lack of user control [8]. In comparison interactive video is especially suitable for engaging the learner by providing him/her with the essential elements of 'control' and 'challenge'.

Interactive video can be defined as, "the use of computer systems to allow proactive and random access to video content based on queries or search targets" [5]. The on screen controls (e.g. skip screen, pause video) eliminates the linearity associated with traditional video. This provides the learner with complete control of their learning experience and the speed with which they learn [5]. The interaction between the learner/player and the video enhances engagement and curiosity, which are important factors in stimulating the learning process [7]. This can be further enhanced through the use of computer simulation, educational games, quizzes/exercises, case studies and the provision of timely feedback on performance as part of the learning experience.

The use of interactive video to enable learning through the process of experiencing failure [9] has great potential for fostering 'deeper learning' [10] and enabling a more effective application of principles learned in the workplace, accelerating the process of skill acquisition [11].

Despite the potential benefits noted above, the very nature of an interactive learning environment implies an increased cognitive load on the learner due to the number of activities required and decisions needed [11]. Although the educational value of instructional video and video streaming is widely documented, the associated impacts of interactive video on the effectiveness of learning are largely unexplored [5] and this is currently being explored in this project.

In 2007/8 with the aid of funding from the University of Southampton's Learning Teaching Enhancement Unit (LATEU), a prototype interactive learning environment for risk assessment health and safety training was developed for traffic engineering safety. An engineering experiment was designed to assess the risk assessment abilities of second year undergraduate students. The prototype was realised through a joint collaboration between the Schools of Civil Engineering and the Environment, Electronics and Computer Science, and Psychology.

In 2008 the Laser safety interactive software was developed from the above prototype engineering experiment and also involved the School of Physics and Astronomy and the Optoelectronics Research Centre.

The concept of interactive training software considers the complex and multivariate problem of applying gaming concepts to the delivery of health and safety education material. The 'game' is based on real laser lab footage, where students, can observe and experience errors in experimental set up from the safety of their own computer.

The traffic engineering case study demonstrated that it was possible to construct the correct cognitive representations that allow knowledge to easily transfer and underpin the principals taught in lectures. Teaching perception and evaluation of risk to any learner group is especially challenging, particularly in dynamic environments. Being able to better engage the learner through the use of visual inputs and not requiring a heavy dependency on language inherent in other learning technologies, interactive video has the power to overcome cross cultural and language barriers as a learning mechanism.

If learning is to occur, and information is to be coded effectively by the cognitive system for long-term retention, it is imperative to design and construct the learning tool in a way that correctly utilises the cognitive attention mechanisms. To achieve this, one needs to design learning with the 'Three C's of Learning' in mind: Control, Challenge, and Commitment [6]. When learners have control over their learning, they are more involved and participate in the learning process which is critical in maximising engagement. Similarly, when the learners are challenged and are committed to the learning process, then they are active and the cognitive system is utilised properly [6]. 


\section{Methodology}

\section{Subject matter}

The subject matter for the Interactive video was designed to cover basic laser safety issues and includes the following;

i. Administrative Laser Safety Controls: in testing, students were expected to notice the absence of appropriate Laboratory Entry Door signage and Laser labelling. Students were also expected to demonstrate an awareness of the dangers of using two lasers of different wavelengths in the same lab by different operators and the need to work with a Laser Safety Officer to mitigate the risk for work in that laboratory.

ii. Engineering Controls: students were expected to notice that lasers and optics needed to be firmly secured before and during laser operation. The students had to be aware of the lack of beam blocks/terminators to prevent the laser beam from exiting the work area. Students were also required to know that index cards should be used during beam alignment, and of the need for key controls on laser power supplies.

iii. Personal Protective Equipment: students were expected to understand the appropriate use of laser safety glasses and how to identify which glasses were appropriate for use.

\section{Target audience}

The aim of this project was to produce a video for undergraduate/postgraduate laser users showing the risks associated with the use of lasers in the lab. The video was filmed showing examples of poor or hazardous working practice under strictly controlled conditions.

The software allows students to interact and engage with the subject matter by requiring them to identify and describe risks through the technique of video 'hot-spotting' (where certain defined areas of the scene which could be down to individual pixel detail can be coded to illicit some response if clicked on by the player) coupled to multiple choice question sets. Table 1 and Figure 1 display the hot-spots and a screen shot of a scene.

Students play the footage and identify issues they feel are hazardous. After the student has played the video and identified the risks, a series of still shots are shown relating the correct method of experiment setup relative to each key risk involved. These are finally shown in real-time when the video is played again.

Table 1. The script of hot-spots of the scene shown in Figure 1.

\begin{tabular}{|c|c|}
\hline Activity & Risks to Identify \\
\hline $\begin{array}{l}\text { User aligns a } \\
\text { laser beam and } \\
\text { optics }\end{array}$ & $\begin{array}{l}\text { - User aims unenclosed } \\
\text { beam upwards } \\
\text { - User wearing watch } \\
\text { - User not wearing } \\
\text { appropriate safety } \\
\text { glasses }\end{array}$ \\
\hline
\end{tabular}

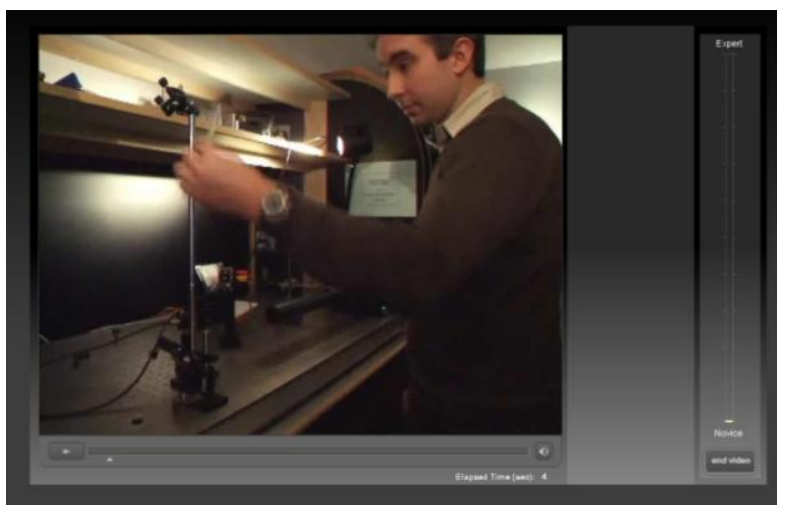

Figure 1. A scene of a laser laboratory used in the video.

\section{Making the Tool Interactive}

The experiment set-up was digitally filmed and lasted just over a minute and a half. The video scenes were meticulously planned and the real eye hazards minimized during the filming by using a laser of less than $5 \mathrm{~mW}$. Camera positioning, hazard identification, incorrect and correct equipment set-up was all planned in set 'scene' sequences.

The digital footage was then edited and imported into the Adobe Flash authoring environment. The interactive video was designed to operate in three distinct stages:

1) The footage is watched and hazards are identified by the student clicking on different locations in the video. Text boxes appear where the student has clicked and the hazard is explained. Once the video is completed, the score that the student has achieved may be submitted to a database along with the students' name. 
2) Each hazard in the video is then shown to the student with text and images to explain why it is a hazard and how to mitigate for the safety risk.

3) The video is viewed again as in 1) however this time each hazard is identified for the student in realtime as the video plays.

During the first stage the video is played through a web browser and can be re-wound at any point until the end is reached. The act of clicking on any part of the footage pauses the video and brings up the hazard identification box (Figure 2). At the same time, the $\mathrm{x}$ and $y$ position of the mouse pointer at that specific point are recorded along with the time the player clicked the mouse button.

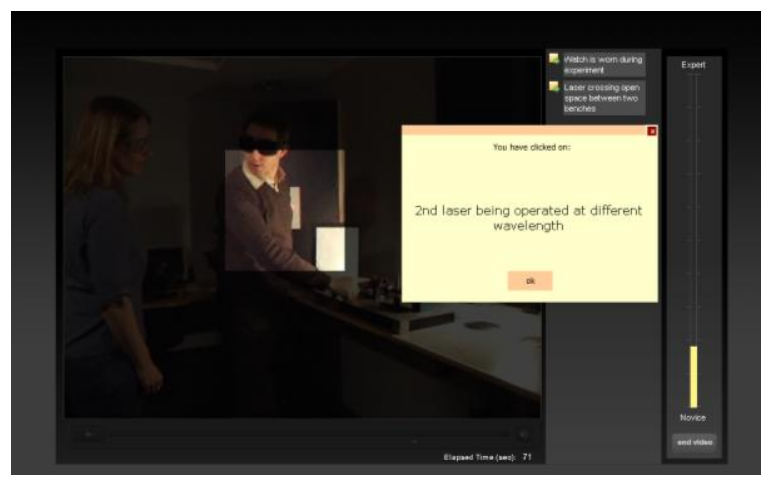

Figure 2. Displaying the hazard identification box.

The hazard identification box describes the hazard at that particular point. After the video has been viewed once in its entirety, a basic calculation (unknown to the player) is carried out comparing the number of hazards identified against the actual number present. If there is a disparity, the system suggests that the student re-examine the video and either looks again for more hazards or review the hazards already identified. As each hazard is correctly identified, the student receives an updated score which appears as a score bar on the right hand side of the screen. If students incorrectly answer the multiple choice questions which appear in the hotpots, they will see their score reduce. Upon reaching the end of the video a second time, the interactive element finishes and the student is given their final score along with a statement about their competency in hazard identification ranging from 'expert' to 'novice'.

Once the video has finished, the official hazards are then shown to the player. A still image of each hazard (taken from the video) is chronologically displayed accompanied by text explaining the hazard along with still images illustrating various solutions as shown in fig 3 . The player can navigate between hazards by using the 'next' and 'previous' buttons. The approach of presenting subjects with images of the correct procedure, post-response follows that adopted by Quentin-Baxter [12].

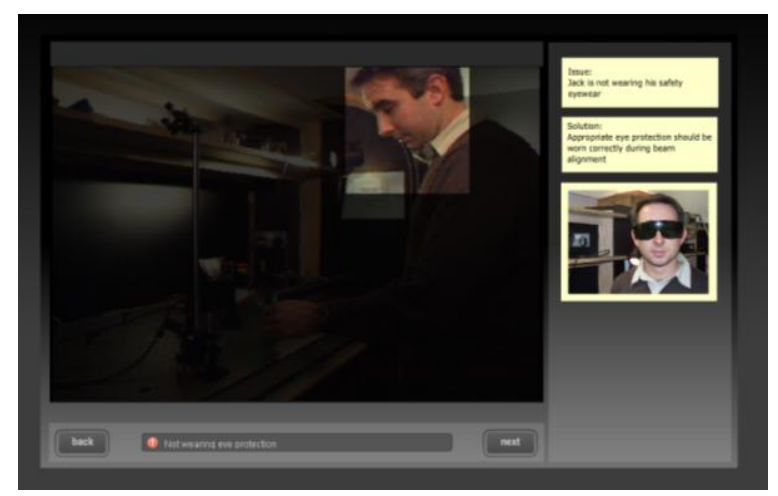

Figure 3. Hazard identification with risk mitigation.

After viewing all the still images of the hazards (e.g. Figure 2), the system then asks the student to watch the video one more time from start to finish. During this phase of the learning cycle, the video is replayed from the beginning and the hazards identified in realtime, the footage momentarily pausing and highlighting each particular issue.

\section{Evaluation of the Interactive Software}

On completion of the prototype an experiment was designed in order to validate its effectiveness as a teaching aid. The experiment compared the effectiveness of the interactive video; to a noninteractive video; a traditional lecture; and a control group who received no additional teaching aid. Participants were selected from a sample of first year Physics and Astronomy undergraduate students who took part in the study as part of safety and risk assessment training. The experimental design was ethically approved and students were free to decline to participate in the experiment. There were 33 participants in total.

At the start of the session, students were briefed on the experimental objectives and methodology. The students then watched a 15-minute clip of the University of Southampton's 'Laser Safety in Higher Education' video. After watching the video students were randomly assigned to receive one of the four additional teaching aids which had been produced for the experiment: a 7-minute recap lecture, the interactive video, a non-interactive video of similar content, and a control group who received no additional teaching aid. To ensure random assignment, students were separated into four segments within the rows of the lecture theatre so that 
there were participants from all rows in each group. The groups were distributed to four different rooms to ensure no interaction or distraction, where they then received their additional teaching aid.

Envelopes were then distributed to the participants within which were consent forms and personal questionnaires. The questionnaire asked for student identification information and questioned whether the student had had any previous experience of working in a laser laboratory, prior to studying at the University of Southampton. The envelope also included instructions on how to complete the test and an answer sheet on which participants could write their responses.

The test involved watching a short video, which illustrated poor safety practice in a laser laboratory. Participants were asked to play the video footage and identify any health and safety hazards displayed, giving free text details of how they would mitigate these problems. The video was played through a web browser which participants could listen to via headphones, and could be paused, re-wound, and replayed as many times as the students felt necessary. During the test, participants were not allowed to discuss issues with each other, thus eliminating the influence of peer interaction on individual performance.

After the test, each participant was required to fill out a questionnaire, which asked them to rate their satisfaction and the effectiveness of the teaching aid they were given as well as to provide feedback on the learning experience. Participants were offered debriefing statements at the end of the study.

It was hypothesized that the interactive video condition would have the greatest effect on learning performance, resulting in higher scores on the subsequent test. It was also hypothesized that the interactive video would result in increased learner satisfaction due to students being actively engaged in the learning experience, thus increasing their motivation and satisfaction.

\section{Results}

Table 2 presents the statistics of the test scores for each condition. These include the number of participants in each group $(\mathrm{N})$, the mean score and the standard deviation.
Table 2. Shows the descriptive statistics including the means and standard deviations of learning outcomes (measured by post-test scores) of participants in different conditions.

\begin{tabular}{|c|c|c|c|}
\hline Condition & $\mathrm{N}$ & Mean & $\begin{array}{c}\text { Std. } \\
\text { Deviation }\end{array}$ \\
\hline $\begin{array}{c}\text { Control group } \\
\text { Non-interactive } \\
\text { video }\end{array}$ & 9 & 45.89 & 19.85 \\
Interactive video & 9 & 73.22 & 13.49 \\
Traditional lecture & 9 & 64.44 & 10.47 \\
\hline
\end{tabular}

\section{Data Analysis}

The results were statistically analyzed using a oneway, between-groups ANalysis Of VAriance (ANOVA). The post-test scores form the dependent variable and the learning condition the independent variable. The results reveal a significant difference among the group means, $F(3,29)=9.10$, p $<0.001$, indicating that the format of teaching had a significant effect on test scores. The results support the hypothesis that the interactive video would have the greatest impact on learning outcome, since participants in this condition obtained the highest percentage of correct scores on average for the posttest $(\mathrm{M}=73, \quad \mathrm{SD}=13)$, suggesting increased knowledge and understanding of health and safety in a laser laboratory. It is interesting to note that participants in the non-interactive video and control conditions obtained similar results $(\mathrm{M}=41, \mathrm{SD}=9$; $\mathrm{M}=46, \mathrm{SD}=20$ respectively). This suggests that simply watching a video passively has no more benefit than having no additional teaching aid at all.

The results also show that the traditional lecture is almost as effective as the interactive video; in fact the error is such, due to the small sample size that it could be argued that it is not conclusive to differential between the two. Due to the interactive nature of a lecture, e.g. the ability to engage the students, and ask students questions to clarify a point - the effectiveness of the lecture was hypothesized to be almost as effective as the interactive video. However a lecture setting cannot familiarize students with real laser safety scenarios - which the interactive and adaptive laser safety video software provides. The interactive software is also able to offer a more effective hazard perception training as a result and 
could also aid deeper learning and therefore better retention of the knowledge.

The results of the questionnaire revealed that most students found the interactive video useful and interesting, 'it engages you to think as opposed to just sit and watch a video'.

Students also stated that they would learn most effectively from both the 15-minute video and interactive video combined than either medium on their own.

\section{Conclusions}

This research to the best of our knowledge is the first to quantitatively validate the effectiveness of an interactive training video.

The paper outlines how an understanding of cognitive processes and the use of new media can complement conventional teaching methods.

The results presented here suggest that the interactive video is more effective than a conventional lecture at reinforcing knowledge and risk perception. However for a definitive answer, a larger sample size is required to reduce the error of the measurement.

Future studies will determine how effective the different teaching methods are in fostering deeper learning and increasing knowledge retention and application.

\section{References}

\section{Journal Paper}

[1] Barford, J. \& Weston, C. (1997) The use of video as a teaching resource in a new university. British Journal of Educational Technology. 28(1), 40-50.

[2] Green, S.M., Voegeli, D., Harrison, M., Phillips, J., Knowles, J., \& Weaver, M. (2003). Evaluating the use of streaming video to support student learning in a first year life sciences course for student nurses. Nurse Education Today. 23(4), 255-261.

[3] Shepherd, K. (2003). Questioning, promoting and evaluating the use of streaming video to support student learning. British Journal of Educational Technology, 34(3), 295-308.

[4] Bates, A.W. (1985). Using video in higher education. Institute of Educational Technology Paper on Broadcasting, No. 243 in Shepherd, K. 2003. Questioning, promoting and evaluating the use of streaming video to support student learning. British Journal of Educational Technology, 34(3), 295-308.

[5] Zhang, D., Zhou, L., Briggs, R., \& Nunamaker, J. (2006). Instructional video in e-learning: Assessing the impact of interactive video on learning effectiveness. Information and Management (43), 1527.

[6] Dror, I.E (2008). Technology enhanced learning: The good, the bad, and the ugly. Pragmatics \& Cognition, 16, 215-223.

\section{Conference Paper}

[7] DiPaola, S., \& Akai, C. (2006). Designing an adaptive multimedia interactive to support shared learning experiences. International Conference on Computer Graphics and Interactive Techniques ACM SIGGRAPH Educators program

\section{Book}

[8] Laurillard, D. (2002). Rethinking University Teaching. A conversational framework for the effective use of learning technologies. London: Routledge ISBN 0415256798 .

[9] Schank (1997) Virtual learning: a revolutionary approach to building a highly skilled workforce. McGraw-Hill.

[10] Bloom, B. (1956) Cognitive Domain. Taxonomy of Educational Objectives. Sage.

[11] Schwan, S., \& Riempp, R. (2004). The cognitive benefits of interactive videos: learning to tie nautical knots. Learning and Instruction, 14, 293-305.

\section{Online resource}

[12] Quentin-Baxter, M. (2007) Resource of video images from a rat dissection. [www document]. URL http://www.ltsn-01.ac.uk/resources/features/rats/. Retrieved online 04/06/07.

\section{Meet the Author(s)}

Dr Tom Cherrett is a lecturer in the School of Civil Engineering and the Environment based in the Transportation Research Group. His main research areas are in fields of freight and logistics management but his teaching areas also include construction management and it is mainly through 
this area that his research interests in health and safety education, particularly risk assessment have come about.

Dr James Gates is currently a research fellow at the Optoelectronics Research Centre (ORC) at the University of Southampton. $\mathrm{He}$ has a broad experience in nanophotonics and planar optical engineering. James has always been heavily involved in photonics outreach and education and over the past few years has been increasingly interested in novel and effective means of teaching laser safety.

Pearl John is an educator with ten year's experience of teaching basic laser safety. Pearl taught on the worlds first three years Photonics course at high school level in Missouri, USA from 1998-2003 and now works at the University of Southampton, UK. Pearl along with a team of academics from the Schools of Psychology, Civil Engineering, Electronics and Computer Science and the Optoelectronic Research Centre - is researching ways to create novel and effective means of teaching laser safety. The research is supported by the University's Learning and Education Teaching Unit. Pearl received her basic laser safety training from the Laser Institute of America in 1998.

Miss Laura Holdaway-Salmon is a final year undergraduate studying Psychology at the University of Southampton. Laura's final year project investigates the impact of interactive video on learning outcome and learner satisfaction, in comparison to a non-interactive video and a traditional lecture. The data is presented in this paper.

Joseph Price is the e-learning web designer for the Learning Societies Lab research group and is responsible for providing web design and development services and participating in web related development work for research projects within the department.

Dr Gary Wills is a Senior Lecturer in Computer Science at the University of Southampton, UK. He is a Chartered Engineer, a member of the Institute of Engineering Technology and a Fellow of the Higher Educational Academy. Gary's main research interests are in Personal Information Environments (PIEs) and their application to industry, medicine and education. PIE systems are underpinned by Service Oriented Architectures, adaptive systems, interoperable eassessment systems, and advanced knowledge technologies.

Dr Itiel Dror holds a doctorate in cognitive neuroscience from Harvard University and specializes in the fields of human cognition and learning. His interest and experience is in taking scientific knowledge and theoretical academic models about the human brain and cognition, and translating them into practical ways to improve and affect human performance at the workplace. Much of his work relates to learning and skill acquisition, and how technology can aid in changing behaviours. 